simplest means of transport." . . . " Therefore the Coniferæ and Cicadia, no doubt, were anemophilous, like the existing species of these groups." . . . "A remarkable fact with respect to anemophilous plants is that they are oten diclinous." For reasons which he gives, Mr. Darwin considers that this "may be attributed to anemophilous plants having retained, in a greater degree than the entomophilous, a primordial condition, in which the sexes were ceparated and their mutual fertilisation effected by means of the wind." . . . . "If this view is correct, plants must have been rendered hermaphrodites at a later though still very early period, and entomophilous at a yet later period, namely, after the development of winged insects." He subsequently points out, however, that " under changing conditions of life.... some bermaphrodite plants, descended, as we must believe, from aboriginally diclinous plants, have had their sexes again separated " and he names as an example, Lychnis dioica. It is only in the case of plants thus reverting that dimorphism can be held to be a transitional stage.

Prof. Thiselton Dyer, in his notice of Mr. Darwin's book in NATURE (vol. xv., p. 329), maintains an opposite view. "It would not be difficult to show that all through the vegetable kingdom the hermaphrodite condition precedes the dicecious." Demurring to Mr. Darwin's conclusion that the monœcious condition "is probably the first step towards hermaphroditism," he considers it " not improbable that precisely the converse may be more true." : . . . "To throw light on the question whether the primordial plant was diclinous or not," he discusses the manner in which it probably originated "from some plant-form not distantly related to Selaginella," and arrives at the conclusion that the first flower would probably be extremely inconspicuous; destitute of colour and hermaphrodite.

How would it be, however, if, instead of regarding the sporangiiferous cone or spike of Selaginella as the homologue of a single flower, we compare it rather with the spike of Carex, say, for example, C. pulicaris? The spike in this species is, like the other, "composed essentially of an axis having modified lateral appendages." The glumes of the sedge correspond to the scales of the lycopod; in the axils of the upper are found the "male structures"--in Selaginella, sporangia containing microspores; in Carex, anthers containing pollen; in the axils of the lower are found the "female structures"-in Selaginella, sporangia containing macrospores; in Carex, ovaries containing each an ovule. There is then not even the difference that the position on the axis of the male and female structures is inverted. From C.pulicaris, with its single spike, the passage is easy to species that have several spikelets, each inale at the top and $\mathrm{ftmale}$ below ; or to others that have the upper spikelets wholly male, the lower ones wholly female. The same arrangement of male and female elements is found in Typha and Sparganium, in most of the Aracex, to which order belong the oldest fossil monocotyledons, and is preserved even in Sagittaria, although in the last the flowers are of a much higher type, being provided with petalloid perianths. So far as the comparison with Selaginella is concerned, does it not favour the production in the first place of unisexual flowers, at least as much as of hermaphrodite?

Newton le Willows

\section{The Rocks of Charnwood Forest}

SOME letters appeared in NATURE a few months ago upon the rocks of Charnwood Forest. In one of them it was suggested that the syenitic bosses of Markfield and Groby might be more ancient than the surrounding slates and grits. Some of your readers may therefore te interested in learning that we have now ascertained from unquestionable evidence in two places that the syenite is intrusive in these rocks, and, as we believe, in some of the highest and latest rocks of the series. We reserve the details of the sections and localities for a paper which we hope shortly to communicate to the Geological Society.
s:. John's College, Cambridge,
March 20
T. G. BONNEY
E. HILL

\section{Southern Double Stars}

Notring some queties in your November numbers (in the "Astronomical Column") respecting some soutbern stars, I inclose you some extracts from our occasional observations that refer to the objects named in those and some previous numbers :-
Southern Double Stars.-Measures wilh 8-inch Refractor.

\begin{tabular}{|c|c|c|c|c|c|}
\hline 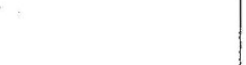 & Pos. & bit. & $\begin{array}{l}\text { No. } \\
\text { Obs. }\end{array}$ & Epoch. & \\
\hline 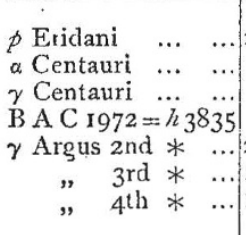 & $\mid$\begin{tabular}{c|}
0 \\
$237 \cdot 3$ \\
$50 \cdot 6$ \\
$8 \cdot 5(?+180)$ \\
$10 \cdot 0$ \\
214.8 \\
$151 \cdot 1$ \\
$141 \cdot 3$
\end{tabular} & \begin{tabular}{|c|}
11 \\
5 \\
$3 \cdot 9$ \\
$1 \cdot 3$ \\
$2 \cdot 7$ \\
$42 \cdot 5$ \\
$62 \cdot 6$ \\
$94 \cdot 3$
\end{tabular} & $\left.\begin{array}{l}2 \\
3 \\
1 \\
5 \\
2 \\
2 \\
2\end{array}\right\}$ & $\left.\begin{array}{r}1877.03 \\
1876.72 \\
1876.63 \\
1876.98 \\
1877.03\end{array}\right\}$ & $\begin{array}{c}\text { Magni- } \\
\text { tudes } \\
2-4 \frac{1}{2}-8-9 \frac{1}{2}\end{array}$ \\
\hline
\end{tabular}

Melbourne Observatory, January 22

Robt. L. J. Ellery

\section{Ship's Chronometers}

$\mathrm{W}^{\prime} \mathrm{E}$ have read with much pleasure your notice (vol. xv. p. 403) of Sir William Thomson's lecture on Navigation, and are prepared fully to endorse your remarks as to the value of Mr. Hartnup's system of rating ships' chronometers, by which account is taken of the change of rate due to change of temperature.

It is but fair to mention, however, that the principle upon which this system is founded was thoroughly investigated by experiments upon a large number of chronometers by $M$. Lieusous, of Paris, some thirty or forty years ago ; acting upon his suggestions, and after independent investigation conducted in our chronometer manufactory some six years ago, we produced a table for the use of captains and others using ships chronometers, which was fastened in the chronometer case, with a small thermometer in front of it, in such a way that the top or upper end of the column of mercury indicated, without any calculation whatever, the mean rate that should be given every day to the chronometer until some considerable change of temperature had taken place (say $3^{\circ}$ ), when the new position of the top of the mercury column again showed the new rate to be used in working the chronometer.

We did not introduce this plan to the navigating public generally, as we feared that sufficient trouble (small though it actually be) would not have been taken in the use of it, also for another reason, i.e., neariy every chronomeler that we have tested has been found to require a different daily coefficient for a change of temperature of $\pm \mathrm{I}^{\circ}$, and ships rarely remain sufficient time in port for us to determine this coefficient after allowing for the time necessary to clean the chronometer.

But, as our system of tabulation may be of interest to your readers and may possibly be available for otlier purposes, we give it you as briefly as possible.

From our experience (which agrees with that of Liensous and of Hartnup) we find that the ordinary compensation balance without auxiliary, causes the chronometer to go at its fastest rate (or in other words to lose least) at a point of the thermometric scale somewhere between $55^{\circ}$ and $70^{\circ} \mathrm{F}$, , usually at $60^{\circ}$ or $65^{\circ}$, and that from $25^{\circ}$ to $30^{\circ}$ above or below that "fastest point" the chronometer loses or goes slower on its fastest rate by an amount that is determined by multiplying the square of the difference in temperature between the new point and the "fastest point" by the coefficient of temperature for a change of $1^{\circ}$ above or below the "fastest point," i.e., by the amount that a chronometer goes slower for having its temperature increased or diminished by $\mathrm{I}^{\circ}$.

This is, however, only true so long as two conditions are adhered to ; the first condition being that the "fastest point" (which can be moved at will by the chronometer maker), shall not be taken outside the limits of $55^{\circ}$ to $70^{\circ}$, that is, the rule will apply from $30^{\circ}$ to $95^{\circ}$ but not beyond, even though the "fastest point" should be moved up to $80^{\circ}$ or down to $40^{\circ}$; beyond these points a new law applies, and instead of squaring the difference of temperature and multiplying that quantity by the coefficient of temperature, this latter must be multiplied by the difference of temperature (always reckoned from the "fastest point " of the chronometer under trial) raised to a power between the square and the cube, or $x \frac{5}{2}$, for which good reasons can be given.

This being explained, it will be easy to perceive the use of the 